\title{
Editorial
}

\section{Where do we want to go?}

\author{
Werner Waldhäusl
}

The changing of the guard is always a time to thank, reflect and look to the future. For Diabetologia and myself, our first wish must be to thank Prof. E. Ferrannini (Editor-in-Chief 1994--1997) and his crew for their superb efforts and service, which have remarkably strengthened our Journal.

Well guided by the advice provided so generously by the Pisa team led by Prof. Ferrannini and his managing editor, Sarah Hills, the northward transfer of the Editorial Office to Vienna which started on $1^{\text {st }}$ October has been a smooth operation, managed by Elise Langdon-Neuner. The more difficult part, however, will be to meet the standards set by my predecessor, as he managed not only to increase the size of Diabetologia from 1200 pages in 1994 to its now 1500, but also the Journal's momentum by attracting some of the best work done in diabetes research. Diabetologia's impact factor, at present 5.4, has in turn considerably increased. In addition, discussion has been fostered by letters to the editor, a controversy section and Rapid communications. These initiatives will be maintained and extended. Furthermore, the endangered species of clinical research will be promoted by encouraging case reports highlighting clinical problems and perspectives. No attempts will, however, be made to split reports of clinical and basic research, both being just different sides of the same diabetes research coin.

Our research nowadays is confronted with the dilemma that hyperglycaemic disorders, recently reclassified by etiology [1], may develop from many causes either leading to beta-cell destruction or to impaired insulin action. Paradoxically, while much work is done on the pathophysiological and clinical sequelae of the disease, very little research is undertaken in the field of prevention of Type II (non-insulindependent) diabetes, a disease which is largely precipitated by environmental factors inappropriate to the human organism, particularly in the industrialised world. It is indeed amazing how many efforts are made to develop drugs for a disease which is rare in physically active populations and those deprived of access to lavish food supply, but dominant in a world of calorie excess. Similarly, there are too few longterm assessment studies of educational programmes used to instruct diabetic patients on how to cope with their disease. It is for this reason that any evidence based reports on these issues, including longterm effects of modes of Type II diabetes prevention and care, will be particularly welcome for publication in Diabetologia. Thus we hope to broaden the basis for future preventive and therapeutic action.

Contrary to common opinion, and although diabetes research has successfully analysed many aspects of diabetes mellitus in much detail over the years, the great breakthroughs are still to be made. To neglect this is self-deception as long as we persist in treating Type I (insulin-dependent) diabetes with insulin without any option of prevention and Type II diabetes in a way which has basically remained unchanged for the past 40 years. Therefore, I wish to encourage young investigators to accept the challenge and test new, as yet unasked hypotheses, instead of asking the predictable and doing 'lateral' research. We should all remember Darwin's dictum `all observation must be for or against some view (hypothesis) if it is to be of any service' [2]. Diabetologia will be pleased to publish such reports, short and clear even if negative, as long as the questions asked are new and the methodology used sound.

To foster co-operative research between academia and the pharmaceutical industry and to rid such welcome and necessary interaction from the smell of clandestine operation, authors will be requested to inform their readers of any financial support they may have received. Further, to better inform the readers abstracts are in the future to precisely state what is new in a given study. This will not only alert the reader to study a report in detail but also act to assist the authors in focusing their message.

Since it is a challenge to all diabetologists to keep up with new developments in diabetes research, Diabetologia will continue to be eager to publish all research news pertinent to diabetes to thereby help both to focus diabetes research and to promote diabetes care. This unique blend of research and assessment of clinical practice is to be cherished. The members of the European Association for the Study of Diabetes, their friends all over the world and all those interested in improving the lot of diabetic patients are invited to continue to submit their finest research for publication in Diabetologia and to further elevate its standing.

\section{References}

1. The Expert Committee on the diagnosis in classification of diabetes mellitus (1997) Report of the expert committee on the diagnosis and classification of diabetes mellitus. Diabetes Care 20: 1183--1197

2. Darwin C. In: Darwin F, Seward AC, (eds) I (1903) More letters of Charles Darwin. Appleton, New York, p 195 